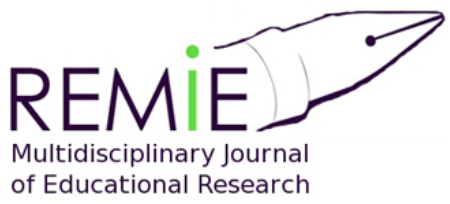

Hipatia Press

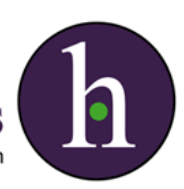

Instructions for authors, subscriptions and further details:

http://remie.hipatiapress.com

\title{
"Since Feeling is First": Exploring the Affective Dimension of Teacher Licensure Exams
}

Emery Petchauer ${ }^{1}$, Kira J. Baker-Doyle ${ }^{2}$, Lynnette Mawhinney ${ }^{3}$, Brian Ciarkowski ${ }^{4}$

1) Oakland University. United States

2) Arcadia University. United States

3) The College of New Jersey. United States

4) Bloomfield Hills School District. United States

Date of publication: June $15^{\text {th }}, 2015$

Edition period: June 2015 - October 2015

To cite this article: Petchauer, E., Baker-Doyle, K. J., Mawhinney, L., \& Clarkowski, B. (2015). "Since Feeling is First": Exploring the Affective Dimension of Teacher Licensure Exams. Multidisciplinary Journal of Educational Research, 5(2), 167-195. doi:10.17583/remie.2015.1495

To link this article: http://doi.org/10.17583/remie.2015.1495

\section{PLEASE SCROLL DOWN FOR ARTICLE}

The terms and conditions of use are related to the Open Journal System and to Creative Commons Attribution License (CC-BY). 


\section{"Since Feeling is First": Exploring the Affective Dimension of Teacher Licensure Exams}

Emery Petchauer

Oakland University

Lynnette Mawhinney

The College of New Jersey
Kira J. Baker-Doyle

Arcadia University

Brian Ciarkowski

Bloomfield Hills School District

\section{Abstract}

Teacher licensure exams directly shape the racial demographics of the teaching profession. This is particularly the case for "basic skills" exams that are program entrance requirements in the United States and expanding into other countries. This qualitative study explored an important yet overlooked dimension of these exams for test takers: emotional and affective states. Specifically, we were interested in the affective dimension of the test-taking event. Our findings reveal a number of positive and negative affective states that both African American and White preservice teachers experience during the exam and the processes of appraisal that produce these states. Our findings also highlight the importance of preparation activities prior to the exam to help alleviate negative affective states during the exam.

Keywords: licensure, certification, testing, race, affect, emotion, teacher education 


\section{"Porque Sentir es lo Primero": Explorando la Dimensión Afectiva de los Exámenes de Licencia para Profesorado}

Emery Petchauer

Oakland University

Lynnette Mawhinney

The College of New Jersey
Kira J. Baker-Doyle

Arcadia University

Brian Ciarkowski

Bloomfield Hills School District

\section{Resumen}

Los exámenes de licencia para profesorado dan forma de manera directa a la demografía racial de la profesión docente. Éste es particularmente el caso de los exámenes de "habilidades básicas", que son requisitos de ingreso al programa en Estados Unidos y que están expandiéndose a otros países. Este estudio cualitativo exploró una dimensión importante pero poco explorada por los examinadores: los estados emocionales y afectivos. En concreto, nos interesamos por la dimensión afectiva del evento de realización de la prueba. Nuestros resultados revelan una serie de estados afectivos positivos y negativos experimentados tanto por los futuros profesores afroamericanos y blancos durante el examen, así como los procesos de evaluación que producen estos estados. Nuestros resultados también ponen de relieve la importancia de las actividades de preparación antes del examen para ayudar a aliviar los estados afectivos negativos durante el examen.

Palabras clave: licencia, certificación, pruebas, raza, afecto, emoción, formación de profesorado 


\author{
since feeling is first \\ who pays any attention \\ to the syntax of things \\ -e.e. Cummings
}

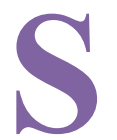

tandardized examinations are integral components of education systems around the world. Data from these exams are used for a variety of purposes, including ranking countries internationally against one another to deciding which schools get funded or closed down in the United States; for individual students, standardized examinations are frequently the gatekeepers to tertiary education and other selective educational opportunities (Ravitch, 2014). The gatekeeping function of high-stakes, standardized exams are particularly evident in the preparation of teachers. In test-heavy countries like the United States, standardized tests are both entrance and exit requirements for most teacher education programs (Petchauer, 2012; Wang, Coleman, Coley, \& Phelps, 2003) and thus have a tremendous influence on who is permitted to enter the professional pipeline and eventually become a teacher.

In light of this gatekeeping function, licensure exams have been closely studied with regard to their influence on the teacher workforce, with particular attention to racial and ethnic diversity. Large-scale statistics indicate significant pass rates gaps between People of Color and Whites (Angrist \& Guryan, 2007; Nettles et al., 2011). Consequently, these exams have functioned to reduce the racial and ethnic diversity of the teaching profession in the United States. In response, researchers have explored preservice teachers' perspectives on the exam and preparation (BakerDoyle \& Petchauer, in press; Bennett, McWhorter, \& Kuykendall, 2006; Graham, 2013) and their social psychological experiences while taking it (Graham, 2013; Petchauer, 2013; 2014; in press) in order to probe deeper than the large-scale statistics on pass rates.

In this article, we explore an unexamined dimension of the licensure exam experience: emotional and affective states. We do so through interview data collected from 40 pre-service teachers in the United States 


\section{Petchauer et al - Since feeling is first}

over the course of 3 years, as part of a larger study on this topic. Our findings reveal a number of positive and negative affective states that both African American and White preservice teachers experience during the exam and the processes of appraisal that produce these states. Our findings also highlight the importance of preparation activities prior to the exam to help alleviate negative affective states during the exam.

\section{Background Literature}

Anxieties about paper-and-pencil teacher tests and their specific effects on the racial demographics of the profession date back to the 1980s. Many of these concerns were in response to the "testing for competencies" movement of this era and unfolded in a special issue of the Journal of Teacher Education (1984) as well as other venues (Gifford, 1985; Smith, Miller, \& Joy, 1988). Although scholars were most concerned with content area exams and their position as exit criteria for programs, scholars also warned of what might come next: entrance exams to teacher education programs (George, 1985).

Now, basic skills or professional readiness exams developed by thirdparty private companies are standard tools in the United States for determining whether a prospective teacher can enter an education program (Petchauer, 2012). However, this approach is relatively unique to the United States. Aside from England, the majority of countries in Europe and Asia do not use private, standardized tests to determine teacher education candidacy. Most gatekeeping measures elsewhere are developed and determined by the accrediting institutions (Wang et al., 2003). Thus, in the United States, the role of private companies, questions regarding the fairness and validity of standardized testing schemes, and high stakes aspects of the exams have led to much criticism.

Educational Testing Services (ETS) and Pearson are the two main testing companies that create licensure exams in the United States. Research by ETS illustrates the profound effect that licensure exams have on the racial composition of the teaching profession. Nettles et al. (2011) compared the first-time pass rate of over 77,000 Black and White preservice teachers between 2005 and 2009 on the Praxis basic skills exam 
and found that African American test takers are roughly half as likely to pass the exams on their first attempt compared to their White counterparts. Angrist and Guryan (2007) reported that licensure exams also disproportionately reduce the percentages of Latino/a teachers in the United States.

Scholars have responded to these results in different ways. Gitomer, Brown, and Bonett (2011) found that test takers who struggle on basic skills exams are unlikely to pass subsequent content area exams. Consequently, they concluded that basic skills exams are useful tools to screen out underprepared prospective teachers. Other scholars have challenged the relevance these exams have to measures of teacher quality. Using different approximations of teacher quality, multiple studies have concluded that there is little relationship between basic skills exam scores and teacher quality (Angrist \& Guryan, 2008; Goodman, Arbona, \& de Raminez, 2008; Memory, Coleman, \& Watkins, 2003). In some instances, the predictive validity of licensure exams also varies depending upon racial group (Goldhaber \& Hansen, 2010).

In order to probe deeper than these large-scale statistics, scholars have started exploring test takers' experiences with and perspectives on the exam, mainly through social psychological frameworks. Studies have found that some African American and Latino/a preservice teachers perceive and experience stereotype threat (Steele \& Aronson, 1995) on the exam in coordination with difficulties on the exam, and that they do not believe the exams to be accurate measurements of their abilities (Bennett et al., 2006; Graham, 2013). Petchauer (2013, 2014) explored African American test takers' experiences with the exam but expanded upon previous work in theory and design. Reframing the licensure exam as a test event (a guiding concept we give further attention to in the next section), these studies have focused on how test takers experience the comprehensive "event" of the exam with attention to how it may become a racialized experience. This work has used identity contingencies and situational cues (Steele, Spencer, \& Aronson, 2002) to identify what it is in the test event that signals judgments, treatments, or stereotypes to test takers. The findings indicated that the licensure exam can become a racialized experience through interactions with proctors and other test takers that signal negative ideas 


\section{Petchauer et al - Since feeling is first}

about Black test takers' intelligence, test taking abilities, and character (Petchauer, 2014). This work also found that specific methods of test administration, such as a race demographic survey prior to the test, can make the test a racialized experience when some test takers are aware of the larger racialized discourse about standardized tests and African Americans (Petchauer, 2013). In this study, we move away from these social psychological lenses and toward affective and emotional experiences with licensure exams.

\section{Theoretical Framework: Toward the Affective}

Building upon prior research in this area, we first drew upon Petchauer (2014) to conceptualize teacher licensure exams as a test event.

A testing event includes interactions with proctors, site administrators, and other test takers before and during exams, but like the proverbial "big race" for a runner, it includes a nexus of cognitive and affective processes beyond the specific skills the test is designed to measure. ( $\mathrm{p}$. 127)

Petchauer points to processes such as self-regulation (Molden \& Dweck, 2006), attribution and causation (Weiner, 1986), appraisal of abilities (Bandura, 1986), tacit theories of intelligence (Dweck, 2006), and various identity threats (Steele, 2010) as components of a test event. Most globally, this framework directed us to look beyond score differences and test takers' beliefs about the exam and instead look to understand how they experienced the test event.

We were concerned most specifically with the affective dimension of the experience, given the many ways that affective states shape and interact with cognitive processes (see Blanchette \& Richards, 2009). Consequently, we drew from some key distinctions and ideas in the field of affective psychology to guide our theoretical framework. We use the term affect as an umbrella category for states that are most often distinguished along a positive-negative binary (Gross \& Thompson, 2007; see also Scherer, 1984). These states are stress responses, emotions, moods, and other impulses. Emotions and moods are particularly important to our study, and we use Bower and Forgas' (2000) framework to distinguished between 
emotions and moods in the following way. An emotion has the property of a reaction; it has "an identifiable cause - a stimulus or antecedent thought, it is usually a spasmodic, intense experience of short duration, and the person is typically well aware of it" (p. 88). For example, one might consider a student who begins a licensure exam and, seeing its difficult content, suddenly feels anxiety. A mood, however, generally lasts longer and is subtle, among other features (Bower \& Forgas, 2000). Here, one might consider a student traveling to the test center to take her licensure exam and feeling calm.

But what counts as an emotion or affective state? Lazarus (1993) argued that we can identify "roughly" fifteen different emotions that can be classified along a negative-positive division. The negative ones include anger, fright, anxiety, guilt, shame, sadness, envy, jealousy, and disgust. The positive ones include happiness, pride, relief, and love. Lazarus added that emotions such as hope, compassion, and gratitude can also be put in this list. These lists, of course, should not be considered exhaustive, and we should not hold onto the exact terms too tightly. Ekman (1992) helps loosen this grip through the notion of emotion families, highlighting that a particular emotion such as happiness can exist as a similar affective state with variations, intensities, and differences. It might be said that a certain emotion family such as anger has a variety of anger expressions (see Ekman \& Friesen, 1978). This helpful division between positive and negative emotions (and affective states more broadly) gave us a useful binary division for data analysis, which we discuss in the following section.

Fredrickson's (1998) broaden-and-build theory outlines one of the many approaches to understanding how emotions and affective states shape cognitive processes that are important to licensure exams. The central hypothesis of the theory is that "positive emotions broaden the scope of attention, cognition, and action, widening the array of percepts, thoughts, and actions presently in mind" (Fredrickson \& Branigan, 2005; p. 315). This hypothesis stands upon a large body of empirical work that has found positive affect makes people more likely to see the interconnections and relatedness between ideas, elaborate on them, think creatively, access memory, and more (see Isen, 2000). Affect can also be an information source "infused" into a person's cognition, thus influencing learning, 


\section{Petchauer et al - Since feeling is first}

attention, memory, and other processes (Forgas, 1995). Predictably, negative emotions can have converse effects, narrowing the range of available reactions and options in one's mind (Fredrickson \& Branigan, 2005; p. 315).

With emotions, there is another essential component of the process to consider: appraisal. Roseman and Smith (2001) pinpoint that "emotions are elicited by evaluations (appraisals) of events and situations" (p. 3). That is, emotions and affective states to not thrust themselves upon people devoid of context, nor do environments (such as a testing environment) impose emotions upon test takers. Rather, it is how people interpret events with respect to their goals, motives, and beliefs that cause emotions (see Scherer, Schorr \& Johnstone, 2001). Returning to the anxious student in the example above: the experience of anxiety is not without context. Upon beginning the exam, he appraises the difficulty of it against his beliefs about his capabilities and his goal to pass the exam in order to become a teacher. Conversely, consider another student taking the exam next to him. She opens the same exam and experiences the emotion of relief because the content seems within her skill range. Her appraisal process leads to a different emotional experience. Both affective states (anxiety and relief) involve goals, motives, and beliefs about their professional need to pass the exam and their abilities to do so.

Overall, these theoretical components directed us to make a division between positive and negative affective states with regards to participants' experiences in the test event, which we illustrate in the following section. We also paid attention where appropriate to the appraisal processes that led to test takers' emotional and affective states in order to understand what brings them about during the test event.

\section{Methods}

Participants in this study were 40 preservice teachers attending two institutions in the Northeastern United States. One of these institutions was "Douglass College," a public institution with a majority African American enrollment of approximately 2,400 students. The other was "Park University," a satellite campus of a large, public university with a majority 
White enrollment of approximately 3,000 students. We use pseudonyms for all names throughout this article. Table 1 presents relevant demographic information about our sample. Throughout this article, we use the terms White to refer to participants with European backgrounds and alternate between Black and African American for participants of color because they identified with both terms.

Table 1

Participant demographics

\begin{tabular}{|l|l|}
\hline \multirow{3}{*}{ Gender } & 8 Male \\
\cline { 2 - 2 } & 32 Female \\
\hline \multirow{2}{*}{ Race/Ethnicity } & 31 Black \\
\cline { 2 - 2 } & 8 White \\
\cline { 2 - 2 } School & 1 Latino/a \\
\cline { 2 - 2 } & 9 Park University \\
\hline \multirow{2}{*}{ Age } & 31 Douglass College \\
\cline { 2 - 2 } & 38 Age 18-24 \\
\cline { 2 - 2 } & 1 Age $25-39$ \\
\cline { 2 - 2 } & 1 Age $40+$ \\
\hline
\end{tabular}

Participants at both institutions had to pass the basic skills exam before being admitted into the teacher education major. However, exam preparation was largely centralized at Douglass College and decentralized at Park University. Douglass provided a voluntary preparation "cohort" workshop that students attended in varying degrees. The cohort was a weekly 75minute preparation workshop where participants learned about the test 


\section{Petchauer et al - Since feeling is first}

format, worked on sample problems, and strategized about taking the exam. Serving as vicarious models of success, students who had already passed the exam also gave advice and encouragement to students attending the preparation cohort. As a small teacher education program of roughly 50 students, the institution also provided transportation for students to a testing center in order to take the exam. Park University, with a teacher education program of about 70 students, provided no formal support systems for students. The university provided general information about the exam, such as how to register, but students were expected to prepare for it on their own if necessary, which some did. We make note of these different preparation opportunities across institutions and their roles in our findings below.

\section{Data Collection}

Following previous work on this topic (e.g., Bennett et al., 2006; Graham, 2013; Petchauer, 2014), we selected focus group interviews as our primary tool to understand how participants experienced the test event. We selected a focus group approach since there were many collective experiences associated with the exam across both institutions. These collective experiences included sharing relevant information, preparation and study, waiting together before and after the exam at the test site, and sharing challenges, successes, and advice. Although the test event itself was an individual experience, many of the experiences surrounding it were collective.

We conducted 12 focus group interviews (lasting between 60 and 75 minutes) within a two-week window after participants had taken their Praxis basic skills licensure exam. Students took the exam in both paper-based and computerized formats at a variety of different test centers. Among the questions in these interviews (see Appendix), two question/activities were most critical to our focus on emotion and affective states:

1. What words come to mind when you hear the word "Praxis"?

2. What words describe how you felt while actually taking Praxis?

Following the protocol in Petchauer (2014), we printed each of these questions separately on poster-size posts-its. We read and explained the questions to participants, and then gave them markers to write their 
responses on the post-its. After reassembling the group, we then used the words and phrases on these post-its as starting points to discuss their experiences with the licensure exam. All interviews were recorded and transcribed verbatim, resulting in 193 pages of single-spaced text.

\section{Data Analysis}

We organized the data in Dedoose, a mixed methods platform for data analysis. Data analysis began with two researchers independently, inductively analyzing one transcript from each of the three groups to create an initial list of codes. Following the theoretical framework, these coders paid attention to the feeling and affect words that students listed and the meanings they attached to them through discussion. As a form of check coding (Miles \& Huberman, 1994), they then compared results from this initial coding procedure to clarify concepts and make modifications to the coding schema before using this framework to code all data.

After clarification and modifications, the two researchers then applied these coding procedures to the entire corpus of data. They also wrote analytical memos throughout this process, which we refer to below. This process resulted in $91 \%$ reliability agreement between the two analysts. We then discussed discrepancies between the coding decisions and came to agreement about each of them. This process satisfied our standard of coder reliability and triangulation for this stage of data analysis.

In order to move toward some more general yet grounded dimensions of the testing experience, we then merged a number of these codes into macrocodes. Guided by our theoretical framework, we called these positive affective states and negative affective states. We also developed a code of mustering up confidence through writing reflective memos. These were instances in which students discussed a positive affective state but by trying to create it during the test event (i.e., muster it up). We saw this as a form of regulation, which is an important cognitive function (Roseman \& Smith, 2001), but separate from experiencing a positive affective state. Consequently, we ensured that data in this code did not overlap with data coded as positive affective states. Table 1 illustrates this code-merge process as well as the number of datum in each code, parenthetically noted. 
Table 2

Coding process

\begin{tabular}{ll}
\hline Initial codes & Resultant macro-codes \\
\hline $\begin{array}{l}\text { Stress, pressure, nervousness (28); } \\
\text { annoyed (3); fear/scary (8); }\end{array}$ & Negative affective states (53) \\
mad/angry (3); upset (2); & \\
uncomfortable (9) & \\
\hline $\begin{array}{l}\text { Calm \& comfortable (11); confident } \\
\text { (15); relief (12); not stressing (2); }\end{array}$ & Positive affective states (43) \\
excited (2); success (1) & \\
\hline $\begin{array}{l}\text { Confidence (4); maintain positive } \\
\text { outlook (18); keep goal in mind (4) }\end{array}$ & Mustering up confidence (26) \\
\hline
\end{tabular}

\section{Findings}

We organize the findings below by three main sections. The first two of these sections deals with positive affective states and negative affective states. Within each of these two sections, we share data to illustrate these affective states and how they are brought about in the test event. The third section focuses on instances in which participants attempted to produce affective states or when they reported disaffected states. Through the findings section we put in italics the words and phrases that students wrote on the discussion scrolls as entry points to discuss their affective experience of the test event, and we maintain any punctuation marks or symbols they added as well. Given the gaps in passing along the lines of race, we also note each speaker's race/ethnic identification to give a picture of how distributed these affective states are across race. 


\section{Positive Affective States}

Interview data suggest a variety of different reasons behind positive affective states among test takers. One of these reasons was seeing material on the exam and appraising that it was within their skill range. This process was oftentimes in light of what students had studied while preparing for the exam. Brandy, a White student at Park University, noted this while discussing why she felt relief: "I was relieved when I found out the test was pretty similar to what I already took and passed. So I tried to stay focused and breathe [laughs]. And then it was over."

African American test takers also demonstrated this too, as noted by Tamara at Douglass College, who was up-front about her struggles taking the math portion of the exam yet still felt confident at times during it.

I said confident. Even though I didn't study as hard as I could have, the stuff that I did study, it came to me during the test. So that kind of piqued my, "Oh, I know one or two things." So that was good.

Similarly, some students experienced positive affective states not because of an appraised relationship between test material and skills but simply because they had prepared. Justin, an African American student at Douglass, unpacked this: "I was relaxed because I felt like I was prepared, like I studied. My moms, she's a teacher, so she had this big book I used."

There were also reasons beyond appraisals of test content, skills, and preparation that accounted for positive moods and emotions. Some students felt relieved, excited, and happy simply because they were taking the exam that had been talked about and built-up so much by their classmates. At Douglass, Shana and Erin (who are Black and White, respectively) connected this reason to a set of words and phrases they put on the scroll that signaled a positive affective state at different points in the day.

Shana: It's over!!! Because I was happy that it was over. Stress-free. Yay! This was during the bus ride [to the exam] because it was the 
day of the Praxis so I was ready to take the test. Yay! It's the day of the test.

Erin: At peace because I don't have to worry about this anymore. I'm taking it now.

One other reason behind positive emotions dealt with the testing center and the perceived competence of the proctors. Patricia, an African American student at Park University, noted the receptiveness of the proctor at the computerized testing center.

Patricia: I felt positive. I felt welcomed at the computer center where I was at. He explained everything to me. He was really, um, he knew his stuff, you know? He knew his job....He just gave me good directions. That made me feel welcomed. When I got ready for the next section, he was like, "Do you want to take a break?" You know, "Do you have to use the bathroom?"....he just knew his stuff.

Although these details about the professionalism and consciousness of the test administrator may seem mundane compared to other data, we saw them as important because some of the identity threats participants experienced through ambiguous or confrontational interactions with proctors in other stages of this study (Petchauer, 2014).

As noted in the Methods section, Douglass College provided a voluntary preparation workshop for their students that met each semester, though enrolling in the seminar was optional. Some of the positive affective states and appraisals for students at Douglass College were based upon their experiences participating in the workshops. Chrissie, a Black student at Douglass, made some of the benefits clear in the following excerpt.

Chrissie: After the cohort I was really confident....I was excited to take Praxis so that I could just take it and just get done and over with it and I know what to expect....But just going to the cohort, I just felt so relieved. I'm like, "Wow." I just really had to sit there and think, "I know all the techniques, why am I so worried?" 
For Chrissie, the cohort gave her a set of strategies to analyze questions for different parts of the test and identify different question types. She was even "excited." Additionally, there were benefits related to the simple act of preparation, as outlined by Bernice, an African American participant at Douglass.

Bernice: Once I got onto the bus I was relieved because everybody was there and just said to myself, "Relax, focus. You went to Praxis cohort, so you prepared, there's nothing to worry about." But at the end I was still nervous because it's like "Oh my god, it's a test," but I was determined, you know, "I got to do this."

In this instance, it was not any specific, test-related preparation from the cohort that helped Bernice to experience a positive affective state. Rather, in the moment when she started feeling nervous, she could remind herself that she prepared and self-regulate accordingly.

\section{Negative Affective States}

Participants experienced negative emotions and affective states for a variety of reasons. Brandy, a White participant at Park University, pointed out a number of different reasons in one concise response.

Brandy: Yeah, I was nervous because it's been a long time since I took a standardized test. And I didn't know how accurate it really was - if I took the pre-test - how it really stood up to the real test. And I also knew I was going to be a junior this year, so I knew that I HAD to pass this test. And I'm also on a limited budget, so I didn't want to have to take it more than once. And then I wanted to, you know - it was over an hour's drive [to the test center] so I couldn't review right before it. So, I guess those are some of the things I was nervous about.

Brandy's overview of why she was nervous pinpoints five reasons: 1) unfamiliarity with the format, 2) uncertainty about the alignment between practice test and the actual exam, 3) a pressing need to pass the test for admission into her program and upper-division courses, 4) the financial cost 


\section{Petchauer et al - Since feeling is first}

of (re)taking the test, and 5) limited study time immediately prior to the test. Recalling the role of appraisals in affective states - particularly in context with a person's goals, motives, and beliefs - there were some key appraisals happening in Brandy's narration stemming from her goal to become a teacher and beliefs about her abilities with respect to the uncertain test content. These reasons for her nervousness and appraisals were also evident among other participants.

While Brandy spoke about negative affective states surrounding the test event, other students experienced these states due to the physical dimensions of the testing space and the strict procedures of test administration, such as proctors assigning test takers to seats so that they could not cheat. Jamie, a bi-racial student at Douglass who identifies as both Black and Puerto Rican, spoke to this.

Jamie: I feel as though it's an uncomfortable situation. It's one thing being at school taking it, but then you get there and then they place you where they want you put. So if I find a seat I'm comfortable in, don't get too comfortable because they might change you to another seat by the window, and it's cold outside, or it's too hot in the classroom. So it could be a little uncomfortable.

Other students echoed this feeling as well by connecting it to other test takers in the room waiting to take the exam. Stephanie and Pamela, both White students at Park University, spoke to this point.

Pamela: When we got in there, we - I don't know if we HAD to but everyone was silent.

Stephanie: Everyone was so nervous.

Pamela: I'm not sure if we would have gotten in trouble if we talked, but no one did. And we just sat there and waited.

The physical aspects of the room and procedures organized by proctors were notable to other test takers in a similar way. Both Lamar and Cameron - in separate interviews, institutions, and test sites - likened the experience to prison. 
Cameron: I feel like it was structured like a prison because there was so much order and everything and the whole time, like, the lady that I had was actually pretty rude. And she was like, the whole time she was just saying like, "You have to be quiet, you have to be quiet." And you go in and raise your hand and there's just so much order and everything. And it just - even in the room, like how neat everything was. And I feel like that made it more stressful. And I know it has to be like that, but that didn't help the stress when it's a high-pressure situation.

Lamar: I felt like I was in prison [others agree]. On time out in one of those rooms, which is a very uncomfortable environment.

Amade: Or ISS, in school suspension.

Lamar: Wooden tables and chairs. I can't think of the word.

Amade: Restricted?

Lamar: Yeah, restricted.

Test rooms and prisons are very different from one another. Yet, we found their mutual selection of the word prison startling not only because of its strong connotative meaning but also because this reference came from different test sites, administrations of the exam, and groups of proctors. Yet, the common experience led them to name it as prison.

Other negative affective states that test takers experienced resided at different level than those discussed so far. These were negative affective states such as nervousness and anxiety that did not appear to be rooted in a clear appraisal or event. We called these "front end" affective states because participants described them as a more-or-less static disposition toward the exam. Keyon, an African American student at Douglass College, illustrated this most clearly.

Keyon: I just get real intimidated with tests. Like when I sit down to take a test, I feel like the test is thinking, "I own you!" [Laughter]. That's how I look at it, "You're gonna listen to me. Walk the way I tell you to walk!" That's how I feel. It's bad that I feel that way. 
Ruby, also African American and at Douglass College, demonstrated this front-end state while explaining why she put nervous on the scroll: "Well, nervous. I always get nervous with tests. I'm always scared that I'm gonna not be ready."

Front-end, static negative affective states typically lacked in-depth explanations and reasons. As in these examples, participants described them succinctly without connecting them to any appraisal of test content or salient quality of the environment. In looking at who was more likely to experience front-end negative affective states, we found that generally it was students who either did not have the opportunity for structured preparation activity or did not take advantage of them.

Participating in structured preparation activities seemed to push students through negative affective states prior to the actual test event. The following exchange between the Petchauer and Douglass students illustrates this process and their thinking.

Petchauer: I'm interested that so far, nobody put up there anxious or anxiety. Often times when I ask this question, a couple people put anxious.... So did you all experience any of those things?

Erin: That happened prior to the - that happened like during the cohort, prior to Praxis. So by the time we took the Praxis, we were all anxioused-out. Can't feel anything.

Bernice: Yeah, just get it done.

Erin: During the time we were taking the cohort, everybody was saying, "That's hard, you're going to have to take it. It's a hard test, it's impossible to pass." Like that whole period.

Petchauer: So when you finally took it -

Erin: - It was like, "Okay, I just have to do this. There's no escaping this."

Petchauer: Would the rest of you agree?

Bernice: Yeah.

Petchauer: [To Bernice] What made you not feel that extreme anxiousness?

Bernice: I guess just having the cohort, coming in and studying.

Wayland: [over Bernice] It was the biggest help out of all. 
Bernice: Yeah, and having somebody that actually passed it talk to you about it.

As this exchange illustrates, it appears that the cohort helped push the students through their anxiety (particularly for Erin) in the midst of other classmates sharing negative experiences with the test. Students who had already passed the exam also came to the cohort to give advice to attendees, and that vicarious model of success seemed to help as well.

\section{Disaffected States and Mustering-Up Confidence}

While some test takers experienced positive affective states for various reasons, others reported positive affective states of a different sort. These instances at first resembled positive affective states due to the words students used during the interview exercises, but these states were of a different nature upon closer examination. Aisha demonstrated one of these cases. In different parts of her focus group interview, she described her state during the exam as calm and chill. Toward the end of the interview, it became clear the roots of this otherwise positive affective state were much different from other test takers. She spoke about "psyching myself out the night before."

Petchauer: How was that?

Aisha: 'Cause I was taking the practice ones, I was like getting on the writing like a 16 out of 38 . I was like, "Gosh!" 'Cause of stuff like that.

Petchauer: So the next morning, why weren't you sort of nervous?

Aisha: 'Cause I figured I can't change it once I do it, so there's no point.

Through this exchange, it became clear that Aisha was calm and chill during the test event but not because she felt prepared, as other students had reported. Rather, the failure experiences while attempting to prepare the evening before left her with little sense of control about her performance on the exam. Her feeling of calmness in this case seems to be derived from a disaffected state. This disaffected state was different from the negative 
affective states, such as nervousness, that some other test takers felt in the midst of unpreparedness.

Some other test takers reported positive affective states, but these were because they tired to produce these states themselves, or as we coded the data, muster them up. Some of these instances involved test takers trying to feel confidence in the midst of uncertainty or nervousness because they knew these negative states would not associate with success. Jasmine shared one specific instance of trying to make herself feel confidence in the midst of nervousness, a negative affective state. She spoke about her state while first starting to take the exam.

I put nervous because everything was riding on it, and I just kept telling myself as I sat there looking at it - not focusing on the test I'm just saying "you can do it, you can do it, you're gonna pass, you're gonna pass."

As we discussed in the previous section, nervousness is a negative affective state that some participants experienced, such as Jasmine in this instance. Her nervousness was rooted in the high-stakes nature of the exam. Recognizing her state, she attempted to coach herself into feeling confident, which is different than actually feeling a sense of confidence, for example, from appraising test content to be easy with respect to one's abilities.

Autumn and Arica reported positive affective states as well but not because they actually experienced them during the test event. Rather, they knew that it would be to their advantage if they were actually to experience these positive affective states.

Autumn: I [put] confident and focused because I know that sometimes when I go into tests, I have to be confident in myself knowing that I know this stuff. So there's no reason why I shouldn't be able to answer the questions accordingly.

Arica: And I think brave because you have to feel a certain way when you are taking a test - like know that you can do it. Have faith and believe that you could be able to pass it and you probably will.

In these instances, Autumn and Arica demonstrate an understanding of the benefits of positive affective states like confidence. However, their 
descriptions lack evidence that they experienced any of these states due to their appraisal of test content and their skills, or some other factor. Their responses point more to the ideal affective states that some test takers desire to have during the exam, rather than what they actually experienced.

\section{Discussion}

The results of this study both extend and challenge prior research on this topic. Bennett et al. (2006) found that African American and Latino/a test takers who took advantage of preparation opportunities were less likely to see bias and other barriers in the exam. Our results align with this finding in that, generally, students who took part in preparation activities experienced fewer negative affective states and more positive affective states during the test event. These affective states were not only because students learned skills to use on the exam. Going through preparation activities gave students a resource to lean upon when they experienced nervous or another negative affective state. Additionally, preparation activities gave students opportunities to work through front-end negative affective states before they stepped into the real test event.

In previous stages of our research, we found that some African American test takers experienced stereotype threats and identity contingencies during the test event, primarily through interactions with proctors (Petchauer, 2013, 2014). These kinds of identity threats often produce negative affective states as well (see Steele, 2010). In the findings of this study, we did not find evidence that negative affective states for African American participants were due to similarly racialized experiences in the test event. Instead, these negative affective states for African American (and White) participants were related to self-appraisals about abilities with respect to test difficulty, aspects of the test environment, and the high-pressure nature of the exam. As with the findings of Graham (2013), our results identify that there is an array of experiences during licensure exams for African American test takers, and some of these experiences overlap with those of White test takers.

With regard to Black and White test takers, the results also add texture to the large-scale quantitative studies on race and licensure exams (Gitomer et 
al., 2011; Nettles et al., 2011). As helpful as these are, they have a tendency to reinforce existing, overly-simplistic ideas about race and standardized test achievement. The positive and negative affective states among participants were not limited to a specific racial classification. Our results suggest that across racial categories, students have both positive and negative experiences with licensure exams. The reasons for positive and negative experiences can be filtered through the subjective and personal lens of race (Petchauer, 2013, 2014), but the affective experiences are not limited by race.

Our results also highlight valuable points pertaining to our theoretical point of entry. This is especially the case with appraisals and their role alongside affective states. To recall, people appraise events and situations in context with their goals, motives and beliefs; these appraisals then elicit emotions (Roseman \& Smith, 2001; Scherer et al., 2001). We saw evidence in our data that preparation activities leading up to Praxis factored into the appraisal process. Practice test and other study activities for exams are usually thought to be valuable because of the knowledge and skills that students can gain from them. This is true. However, it the mere act of preparing can give test takers an experiential resource to draw upon as they appraise events, thus increasing the likelihood that the appraisal (or reappraisal) will result in positive and not negative affective response. It can also push them through more static, negative affective states before they take the exam and have to perform.

Herein lies an important connection to self-efficacy theory (Bandura, 1997), which has been recommended as a relevant dimension of the licensure exam experience (Petchauer, 2012, in press). Physiological and affective states are one source of information from which people develop beliefs about their capabilities in specific domains and tasks (Bandura, 1997). One person might interpret the feeling of nervousness as a sign that she is not prepared for the exam. Another might interpret that same feeling as an indicator that she is excited and ready to perform well. It stands to reason that taking advantage of preparation opportunities before the exam can make students more likely to appraise some physiological and affective states during the actual test event in a manner that has a positive result. One exception to this positive outcome, however, is preparation that gives 
students an initial, significant experience of failure, such as taking a 40question practice test and getting many questions wrong. Direct experience is consistently a more powerful information source of self-efficacy compared to physiological and affective states (Usher \& Pajares, 2008), so reckless preparation may undermine the overall goal of producing positive affective states during the exam.

\section{Implications and Conclusions}

The findings of our study hold implications for both practice and future research. For practice, our study underscores the importance of teacher education programs organizing deliberate and structured licensure exam supports for students and centralizing this process. Our sense is that most institutions, as was the case at Park University, leave students to navigate this process alone. Given how our findings pointed to the preparation cohort at Douglass College, we recommend that teacher education programs consider the benefits of preparing their students for licensure exams. These benefits are academic (familiarization with test content and format) but also affective (pushing through nervousness). We encourage teacher education programs to consider the affective benefits of licensure exam supports as well as the academic ones, particularly through ways that are parallel to the requisite curriculum and thus would not add financial burden to students. Given how exam success directly impacts the racial and ethnic diversity of groups admitted into teacher education programs, these efforts ultimately can help increase the diversity of programs and the profession.

For future research, we encourage scholars to give further attention to the affective dimensions of the test event and what might promote more positive affective orientations toward the exam and positive affective states during the test event. Annoyance, nervousness, and other negative emotions are understandable affective stances toward high-stakes exams that cost students money. However, the psychological literature that grounds this study suggests that there are benefits related to performance that follow from positive affective states. Understanding what pushes preservice teachers toward a positive affective exam orientation (e.g., excited rather than nervous) will likely put them in a better position to perform to their 
capabilities. Similarly, understanding how students affectively regulate themselves during the test event can have equally positive outcomes.

We also encourage inquiry that is guided by the notion of a test event and its different dimensions. Between views of the licensure exam as an unnecessary obstacle (Bennett et al., 2006) or a useful signal (Gitomer et al., 2011), the test event directs researchers first and foremost to test takers in the social and psychological context of the exam and its numerous layers. Additionally, it pushes scholars to explore much more than test content and questions but the intertwined cognitive and affective mechanisms that play into performance. Licensure exams are a (if not the) critical step of professional matriculation for preservice teachers, and the exams directly shape the racial demographics of the profession as well. This status requires scholars to use a robust heuristic to understand it.

\section{References}

Angrist, J. D., \& Guryan, J. (2008). Does teacher testing raise teacher quality? Evidence from state certification requirements. Economics of Education Review, 27, 483-503. doi:10.1016/j.econedurev.2007.03.002

Baker-Doyle, K., \& Petchauer, E. (in press). Rumor has it: Investigating teacher licensure exam networks. Teacher Education Quarterly.

Bandura, A. (1997). Self-efficacy: The exercise of self control. New York:

W. H. Freeman and Company.

Bennett, C. I., McWhorter, L. M., \& Kuykendall, J. A. (2006). Will I ever teach? Latino and African American students' perceptions on PRAXIS I. American Educational Research Journal, 43, 531-575. doi:10.3102/00028312043003531

Blanchette, I., \& Richards, A. (2009). The influence of affect on higher level cognition: A review of research on interpretation, judgment, decision making and reasoning. Cognition and Emotion, 24(4), 561595. doi:10.1080/02699930903132496

Bower, G. H., \& Forgas, J. P. (2000). Affect, memory, and social cognition. In E. Eich, J. F. Kihlstorm, G. H. Bower, J. P. Forgas, \& P. M 
Niedenthal (Eds.) Cognition and emotion (pp. 87-168). New York: Oxford University Press.

Dweck, C. S. (2006). Mindset. New York: Random House.

Ekman, P. (1992). An argument for basic emotions. Cognition and emotion, 6, 169-200. doi:10.1080/02699939208411068

Ekman, P., \& Friensen, W. V. (1978). Facial action coding system: A teachnique for the measurement of facial movement. Palo Alto, CA: Consulting Psychologist Press.

Forgas, J. P. (1995). Mood and judgment: The Affect Infusion Model (AIM). Psychological Bulletin, 177, 39-66. doi:10.1037/00332909.117.1.39

Fredrickson, B. L., \& Branigan, C. (2005). Positive emotions broaden the scope of attention and thought-action repertoires. Cognition and emotion, 19(3), 313-332. doi:10.1080/02699930441000238

Fredrickson, B. L. (1998). What good are positive emotions? Review of general psychology, 2(3), 300-319. doi:10.1037/1089-2680.2.3.300 George, P. (1985). Teacher testing and the historically Black college. Journal of Teacher Education, 36, 54-57. doi:10.1177/002248718503600609

Gifford, B. R. (1985). Teacher competency testing and its effects on minorities: Reflection and recommendations. In E. E. Freeman (Ed.) Educational standards, testing, and access: Proceedings of the 1984 ETS Forth-Fifth Invitational Conference. Princeton, NJ: Educational Testing Service.

Gitomer, D. H., Brown, T. L., \& Bonett, J. (2011). Useful signal or unnecessary obstacle? The role of basic skills test in teacher preparation. Journal of Teacher Education, 62(5), 431-445. doi:10.1177/0022487111412785

Goldhaber, D., \& Hansen, M. (2010). Race, gender, and teacher testing: How informative a tool is teacher licensure testing? American Educational Research Journal, 47, 218-251. doi:10.3102/0002831209348970

Goodman, G., Arbona, C., \& de Ramirez, R. D. (2008). High-stakes, minimum-competency exams: How competent are they for 
192 Petchauer et al - Since feeling is first

evaluating teacher competence? Journal of Teacher Education, 59, 24-39. doi:10.1177/0022487107309972

Graham, A. (2013). Black teachers education candidates' performance on PRAXIS I: What test results do not tell us. The Negro Education Review, 64, 9-36.

Gross, J. J., \& Thompson, R. A. (2007). Conceptual foundations for the field. In J. J. Gross (Ed.), Handbook of emotion regulation (pp. 3-24). New York: Guilford Press.

Isen, A. M. (2000). Positive affect and decision making. In M. Lewis, \& J. M. Haviland-Jones (Eds.), Handbook of emotions (2nd ed., pp. 7594). Hillsdale, NJ: Erlbaum.

Journal of Teacher Education (1984). Testing for Competency [special issue], 35(2).

Lazarus, R. S. (1993). From psychological stress to the emotions: A history of changing outlooks. Annual Review of Psychology, 44(1), 1-21. doi:10.1146/annurev.ps.44.020193.000245

Memory, D. M., C. J. Coleman, \& Watkins. S. D. (2003). Possible tradeoffs in raising basic skills cutoff scores for teacher licensure: A study with implications for participation of African Americans in teaching. Journal of Teacher Education 54, 217-227. doi:10.1177/0022487103251746

Miles, M. B., \& Huberman, M. A. (1994). Qualitative data analysis, 2nd ed. Thousand Oakes, CA: Sage Publications.

Molden, D. C., \& Dweck, C. S. (2006). Finding "meaning" in psychology: A lay theories approach to self-regulation, social perception, and social development. American Psychologist, 61, 192-203. doi:10.1037/0003-066X.61.3.192

Nettles, M. T., Scatton, L. H., Steinberg, J. H., \& Tyler, L. L. (2011). Performance and passing rate differences of African American and White prospective teachers on Praxis examinations. ETS Research Report 11-08. Retrieved August 13, 2011 from http://www.ets.org/Media/Research/pdf/RR-11-08.pdf

Petchauer, E. (2012). Teacher licensure exams and Black teacher candidates: Toward new theory and promising practice. Journal of Negro Education, 81(3), 252-267. 
Petchauer, E. (2013). Passing as white: Race, shame, and success in teacher licensure testing events for Black preservice teachers. Race, Ethnicity, and Education. [Online version] doi:10.1080/13613324.2013.792796

Petchauer, E. (2014). "Slaying ghosts in the room": Identity contingencies, teacher licensure testing events, and African American preservice teachers. Teachers College Record, 116(7), 1-40.

Petchauer, E. (in press). Shall we overcome? Self-efficacy, teacher licensure exams, and African American preservice teachers. The New Educator.

Ravitch, D. (2014). Reign of error: The hoax of the privitization movement and the dangers to America's public schools. New York: Knof.

Roseman, I. J., \& Smith, C. A. (2001). Appraisal theory: Overview, assumptions, varieties, controversies. In K. R. Scherer, A. Schorr, \& T. Johnstone (Eds.) Appraisal process in emotion: Theory, methods, research (pp. 3-19). New York: Oxford University Press.

Scherer, K. R. (1984). On the nature and function of emotion: A component process approach. In K. R. Scherer \& P. Ekman (Eds.) Approaches to emotion (pp. 293-317). Hillsdale, NJ: Lawrence Erlbaum Associates.

Scherer, K. R., Schorr, A., \& Johnstone, T. (Eds.) (2001). Appraisal process in emotion: Theory, methods, research. New York: Oxford University Press.

Smith, G. P., Miller, M. C., \& Joy, J. (1988). A case study of the impact of performance-based testing on the supply of minority teachers.

Journal of Teacher Education, 39, 45-53.

doi:10.1177/002248718803900409

Steele, C. M. (2010). Whistling Vivaldi: How stereotypes affect us and what we can do. New York: Norton.

Steele, C. M., \& Aronson, J. (1995). Stereotype threat and the intellectual test performance of African Americans. Journal of Personality and Social Psychology, 69, 797-811. doi:10.1037/0022-3514.69.5.797

Steele, C. M., Spencer, S. J., \& Aronson, J. (2002). Contending with group image: The psychology of stereotype and social identity threat. In M. P. Zanna (Ed.), Advances in experimental social psychology (Vol. 34, pp. 379-440). San Diego, CA: Academic Press. 
194 Petchauer et al - Since feeling is first

Usher, E. L., \& Pajares, F. (2008). Sources of self-efficacy in school:

Critical review of the literature and future directions. Review of

Educational Research, 78, 751-796. doi:10.3102/0034654308321456

Wang, A. H., Coleman, A. B., Coley, R. J., \& Phelps, R. P. (2003).

Preparing Teachers around the World. Policy Information Report.

Princeton: Educational Testing Service Policy Information Center.

Weiner, B. (1986). An attributional theory of emotion and motivation. New

York: Springer-Verlag.

Emery Petchauer is an Assistant professor of Urban Education at Oakland University.

Kira J. Baker-Doyle is an Assistant professor at Arcadia University School of Education.

Lynnette Mawhinney is an Associate professor of Urban Education at The College of New Jersey.

Brian Ciarkowski is a Spanish Teacher at Bloomfield Hills High School.

Contact Address: Emery Petchauer. Oakland University 470C Pawley Hall, Rochester, Michigan, 48309 USA Email: petchaue@oakland.edu 


\section{Appendix A \\ Interview questions}

1. What are your general feelings about standardized tests? (Probe: what standardized tests have you taken?)

2. Before you took Praxis, how did you predict your performance would be? (i.e., how did you think you would do?). (Probes: On the whole thing? On individual tests?)

3. Scroll exercise 1: What words come to mind when you hear the word "Praxis?" (This question printed on a scroll size post-it, and students write their responses in marker. Discussing response as a group.)

4. Scroll exercise 2: What words describe how you felt while actually taking Praxis? (Can include before, during, and after the test or at any point during the day). (Same instructions as question 3 above.)

5. At what points during the day were you most uncomfortable (i.e., anxious, nervous, etc.)? At what point were you most confortable (i.e., calm, relaxed, etc.)?

6. Where there any instances when your mood, mindset, or feelings quickly changed? For example, you were feeling or thinking one way, and then something made you feel or think a different way.

7. What do you think about standardized test taking abilities? Do you think some people are naturally good test takers, or can people work hard and become good test takers?

8. Are there any other parts of the Praxis test that you want to bring up or that you think we should talk about? (Open ended portion of interview) 